\title{
Retina or visual cortex? The site of phosphene induction by transcranial alternating current stimulation
}

\section{Caspar M. Schwiedrzik*}

Department of Neurophysiology, Max Planck Institute for Brain Research, Frankfurt am Main, Germany

${ }^{*}$ Correspondence: schwiedrzik@mpih-frankfurt.mpg.de

\section{A commentary on}

Frequency-dependent electrical stimulation of the visual cortex.

Kanai, R., Chaieb, L., Antal, A., Walsh, V., and Paulus, W. (2008). Curr. Biol. 18, 1839-1843.

Since the first descriptions of oscillatory synchrony in the cortex, a plethora of studies have provided empirical evidence for correlations between cortical oscillations and perception, attention, and other cognitive functions (Tallon-Baudry, 2009). However, it has remained difficult to obtain causal evidence for a role of oscillatory synchrony in cortical processing. Recent developments in noninvasive brain stimulation techniques might constitute a new approach to this problem (Thut and Miniussi, 2009). In a recent paper employing such a technique, Kanai et al. (2008) report that the visibility of phosphenes elicited by transcranial alternating current stimulation (tACS) depends on the frequency of stimulation. Specifically, at a frequency of about $20 \mathrm{~Hz}$ the lowest intensity was needed to produce peripheral phosphenes. Furthermore, when the eyes of the subjects were closed, this optimum frequency shifted to a frequency of about $10 \mathrm{~Hz}$. Interestingly, these stimulation frequencies seem to correspond to the well known beta $(12-30 \mathrm{~Hz})$ and alpha $(8-12 \mathrm{~Hz})$ frequency bands in the electroencephalogram (EEG), and alpha power in the EEG indeed increases when subjects close their eyes. Based on these ostensible similarities, the authors concluded that "the frequency dependency is caused by interactions with ongoing oscillatory activity in the stimulated cortex", and that "tACS can be used as a noninvasive tool for establishing a causal link between rhythmic cortical activities and their functions".
If this were the case, tACS would potentially be an interesting tool to inquire the causal role of oscillatory synchrony in cortical processing. However, previously published evidence renders the interpretation that tACS interacts directly with cortical activity questionable: It has been suggested that peripheral phosphenes as observed by Kanai et al. (2008) are elicited on the level of the retina, and not in cortical structures.

The first successful attempts to stimulate the visual system by alternating current (AC) were already introduced in the first half of the last century by one of the pioneers of the EEG, Rohracher (1935). He described that peripheral phosphenes could reliably be elicited by AC stimulation with different electrode configurations on the head. The most consistent finding was a frequency optimum in the beta range $(15-20 \mathrm{~Hz})$, irrespective of electrode arrangement. This finding corresponds well to the more recent results of Kanai et al. (2008), which were obtained only with a fronto-occipital montage. Based on the result that the intensity needed to elicit phosphenes increased with distance from the eye, Rohracher concluded that the most likely site of stimulation was the retina (although he also considered an effect of AC stimulation on the cortex).

A few years later, Schwarz (1947) showed that the intensity needed to elicit phosphenes by AC stimulation depends on the adaptational state of the eye. The initial adjustment of retinal sensitivity to background illumination only takes fractions of a second (Meister and Berry, 1999), thus $5 \mathrm{~s}$ of eyes closed as in Kanai et al. (2008) can be considered a case of dark adaptation. During dark adaptation, the susceptibility to AC stimulation shifts to lower frequencies (see Figure 1). These findings were replicated by Meyer-Schwickerath and Magun (1951), and expanded to the field of color vision by Motokawa and Ebe (1952). More definite proof that the site of stimulation was indeed the retina was obtained by Brindley (1955). Brindley used conjunctival

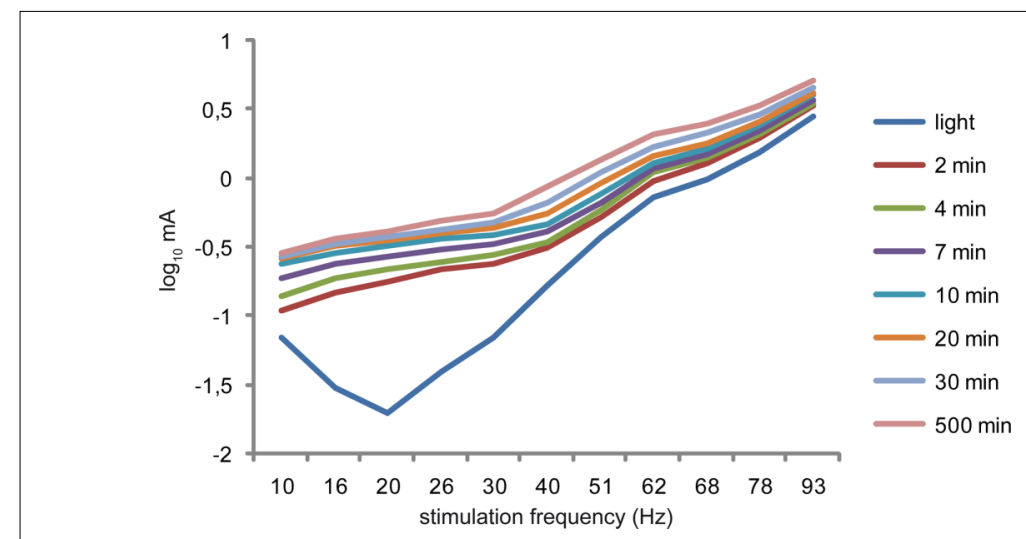

FIGURE 1 | In his experiments, Schwarz (1947) varied the duration of dark adaptation and the frequency of alternating current stimulation. Without dark adaptation, a clear frequency optimum is seen at $20 \mathrm{~Hz}$, whereas differing durations of dark adaptation shift this optimum to lower frequencies (10 Hz) (adapted from Schwarz, 1947, with kind permission from Springer Science + Business Media). 
electrodes which render volume conduction to the occipital cortex highly unlikely. More importantly, he employed pressure blinding to demonstrate the dependence of the phosphenes on the proper functioning of the retinal circuitry. Prolonged (20-40 s) pressure on the eyeball compromises the retinal blood circulation, thus preventing retinal ganglion cells from firing (Fox et al., 1973). This leads to intermittent blindness and to an inability to perceive retinal phosphenes. Brindley concluded that peripheral phosphenes are elicited by excitation of either the bipolar cells or the photoreceptors. The fact that phosphenes can be elicited irrespective of electrode montage, that the intensity needed to elicit them increases with distance from the eye, and that they cannot be elicited after pressure blinding renders the possibility that phosphenes are the result of a direct interaction of AC stimulation with ongoing cortical activity highly unlikely.

Kanai et al. (2008) based their interpretation that tACS directly influences cortical activity solely on the position of their "stimulating" electrode, which was located over the visual cortex. The authors argue that the use of a bigger reference electrode reduces the influence of the current on the cortical tissue beneath the reference because the current density at this site is lower. The validity of this claim could have easily been tested by varying electrode positions (as in Rohracher, 1935). Kanai et al.'s (2008) argument is based on a study that investigated long-term aftereffects of transcranial direct current stimulation (tDCS) on the motor cortex (Nitsche et al., 2007), and not effects that are concurrent with the stimulation. The absence of long-term aftereffects does not imply the absence of current spread from the vertex electrode to the retina.

Although tACS might be used to manipulate cortical oscillatory synchrony under certain conditions, empirical support for this notion is still lacking. Evidence for a direct interaction with cortical rhythms could have been obtained by modeling the current flow, employing pressure blinding, varying electrode positions (for example by exchanging the positions of the stimulating and the reference electrode), or by correlating the optimal stimulation frequency for AC stimulation of a given subject with its individual alpha frequency in the EEG. As long as the site of interaction of tACS with the visual system remains undetermined, whether " $t A C S$ can be used as a noninvasive tool for establishing a causal link between rhythmic cortical activities and their functions" (Kanai et al., 2008) remains an open question.

\section{ACKNOWLEDGEMENTS}

This work was supported by the Max Planck Society. I would like to thank Ryota Kanai, Axel Kohler, Lucia Melloni, Sergio Neuenschwander, Wolf Singer, and Heinz Wässle for their comments on this issue.

\section{REFERENCES}

Brindley, G. S. (1955). The site of electrical excitation of the human eye. J. Physiol. 127, 189-200.
Fox, R., Blake, R., and Bourne, J. R. (1973). Visual evoked cortical potentials during pressure-blinding. Vision Res. 13, 501-503.

Kanai, R., Chaieb, L., Antal, A., Walsh, V., and Paulus, W. (2008). Frequency-dependent electrical stimulation of the visual cortex. Curr. Biol. 18, 1839-1843.

Meister, M., and Berry, M. J. II (1999). The neural code of the retina. Neuron 22, 435-450.

Meyer-Schwickerath, G., and Magun, R. (1951). Über selektive elektrische Erregbarkeit verschiedener Netzhautanteile. Graefes Arch. Clin. Exp. Ophthalmol. 151, 693-700.

Motokawa, K., and Ebe, M. (1952). Selective stimulation of color receptors with alternating currents. Science 116, 92-94.

Nitsche, M. A., Doemkes, S., Karakose, T., Antal, A., Liebetanz, D., Lang, N., Tergau, F., and Paulus, W. (2007). Shaping the effects of transcranial direct current stimulation of the human motor cortex. J. Neurophysiol. 97, 3109-3117.

Rohracher,H.(1935). Über subjektive Lichterscheinungen bei Reizung mit Wechselströmen.Z. Sinnesphysiol. 66, 164-181.

Schwarz, F. (1947). Über die elektrische Reizbarkeit des Auges bei Hell- und Dunkeladaptation. Pflüg Arch. Ges. Physiol. 249, 67-86.

Tallon-Baudry, C. (2009). The roles of gamma-band oscillatory synchrony in human visual cognition. Front. Biosci. 14, 321-332.

Thut, G., and Miniussi, C. (2009). New insights into rhythmic brain activity from TMS-EEG studies. Trends Cogn. Sci. 13, 182-189.

Received: 25 March 2009; published: 18 May 2009. Citation: Schwiedrzik CM (2009) Retina or visual cortex? The site of phosphene induction by transcranial alternating current stimulation. Front. Integr. Neurosci. 3:6. doi: 10.3389/neuro.07.006.2009

Copyright $\odot 2009$ Schwiedrzik. This is an open-access publication subject to an exclusive license agreement between the authors and the Frontiers Research Foundation, which permits unrestricted use, distribution, and reproduction in any medium, provided the original authors and source are credited. 